\title{
Solution of Chance Constrained Programming Problem for Multi-Objective Interval Solid Transportation Problem under Stochastic Environment using Fuzzy Approach
}

\author{
A.Nagarajan \\ Department of Mathematics, \\ PSNA College of Engg. \& Tech., Dindigul, \\ Tamil Nadu, India
}

\author{
K. Jeyaraman \\ Department of Mathematics, \\ Alagappa Government Arts College, Karaikudi, \\ Tamil Nadu, India
}

\begin{abstract}
In this paper, a solution procedure has been given for the Chance Constrained Programming Models For Multi-Objective Interval Solid Transportation Problem under stochastic environment (MOISTP) where the cost coefficients of the objective functions, the source availability, destination demand and conveyance capacities have been taken as stochastic intervals by the decision makers. The problem has been transformed into a classical multi-objective transportation problem where the multiple objective functions are minimized by using fuzzy programming approach. Numerical examples are provided to illustrate the approach
\end{abstract}

\section{KEYWORDS}

Chance constrained programming; Multi-objective interval solid transportation problem; Stochastic programming; Fuzzy programming

\section{NTRODUCTION}

As a generalization of traditional Transportation Problem, the Solid Transportation Problem (STP) was stated by Shell [4] in 1955, which he considered the three item properties in the constraint set instead of two items namely source and destination. He also suggested the situations where the STP would arise, and four cases of STP were discussed according to the data given on the item properties and developed its solution procedure. Basu et al. [5] developed an algorithm for finding the optimum solution for the solid fixed charge linear transportation problem. Although STP was forgotten for long time, because of existing advanced solution methodologies, recently it is receiving the attention of many researchers of this field. Models and algorithms have been developed by many authors [6, 12, 15-19].

In literature, it was found that various effective algorithms were developed for solving transportation problems with the assumption that the coefficients of the objective function, source availability, destination demand and conveyance capacities are specified in a crisp manner. However, these conditions may not be satisfied always. Since in the present situation, the unit transportation costs are rarely constant. To deal the problems with ambiguous coefficients in mathematical programming, inexact and interval programming techniques have been developed by many authors [13, 14, 26, 27].

The STP in uncertain environment becomes important branch of optimization and a lot of models and algorithms have been presented for different problems by different authors $[2,19]$. A.Nagarajan and K.Jeyaraman developed a model for solid fixed cost bi-criterion indefinite quadratic transportation problem, Expected value goal programming model and Chance constrained goal programming model for multi-objective interval solid transportation problem under stochastic environment [23, 24, 25]. S.K.Das et al. [11], developed the theory and methodology for multi-objective transportation problem with interval cost, source and destination parameters. Expected value of fuzzy variable and fuzzy expected value models presented by Baoding Liu and Yian-Kui Liu [7].

The fuzzy set theory concept was first introduced by Zadeh [28]. Linear programming problems with several objective functions was solved by using fuzzy membership functions by Zimmerman [29] and he showed that the results obtained from fuzzy are always efficient. A special type of non-linear membership function was used for the vector maximum linear programming problem [21].

In this paper, the idea of stochastic environment has been employed for MOISTP and a method has been proposed to solve the MOISTP. Using chance constrained programming of random variables, we have constructed an equivalent crisp model to the given MOISTP. To obtain the solution of this equivalent problem, we have used fuzzy programming approach. In order to illustrate the proposed method, numerical examples are provided.

This paper is organized as follows. In Section 2, the basic idea of MOISTP has been given. In Section 3, formulation of crisp objective function and related definitions have been given. The formulation of crisp constraint and Chance Constrained Programming Problem [CCPM] have been given in the section- 4 and section-5 respectively. Crisp equivalent, fuzzy programming approach and different cases of CCPM for MOISTP along with numerical example is given in Section-6, 7 and 8.

\section{MULTI-OBJECTIVE TERVAL SOLID TRANSPORTATION PROBLEM (MOISTP)}

The MOISTP is a generalization of the multi-objective solid transportation problem in which input data are expressed as stochastic variables as well as stochastic intervals instead of point values. These types of problems arise only when uncertainty occurs in data. The decision makers consider it as more convenient to express it as intervals which can be stated as follows. 
Problem-I :

Minimize

$$
\begin{array}{r}
\mathrm{Z}^{p}=\sum_{i=1}^{m} \sum_{j=1}^{n} \sum_{k=1}^{l}{ }_{\left[\mathrm{c}_{L i j k}^{p}, \mathrm{c}_{R i j k}^{p}\right] \mathrm{x}_{\mathrm{ijk}},} \\
\mathrm{p}=1, \quad 2, \quad 3, \ldots, \mathrm{P}
\end{array}
$$

subject to

$$
\begin{aligned}
& \sum_{j=1}^{n} \sum_{k=1}^{l} \mathrm{x}_{\mathrm{ijk}}=\left[\mathrm{a}_{L i}, \mathrm{a}_{R i}\right], \\
& \sum_{i=1}^{m} \sum_{k=1}^{l} \mathrm{x}_{\mathrm{jik}}=1,2,3, \ldots, \mathrm{m} . \quad(2) \\
& \left.\sum_{i=1}^{m} \sum_{j=1}^{n}, \mathrm{~b}_{R j}\right], \\
& \mathrm{j}=1,2,3, \ldots, \mathrm{n} . \\
& \sum_{i=1}^{m} \mathrm{x}_{\mathrm{ijk}}=\left[\mathrm{e}_{L k}, \mathrm{e}_{R k}\right], \\
& \sum_{k=1}^{l} \mathrm{a}_{L i} \geq \sum_{j=1}^{n} \mathrm{e}_{L k} \geq \sum_{j=1}^{m} \sum_{i=1}^{m} \mathrm{~b}_{L j}, \sum_{k=1}^{l} \mathrm{a}_{R i} \geq \sum_{j=1}^{n} \mathrm{e}_{R j},
\end{aligned}
$$

(non-balanced condition is always assumed) (5). Where $\left[\mathrm{c}_{L i j k}^{p}, \mathrm{c}_{R i j k}^{p}\right]$ for $\mathrm{p}=1,2,3, \ldots, \mathrm{P}$ are intervals representing the uncertain cost for the transportation problem; it can represent delivery time, quantity of goods delivered, under used capacity, etc. The source parameter lies between left limit $\mathrm{a}_{L i}$ and right limit $\mathrm{a}_{R i}$, similarly, destination parameter lies between left limit $\mathrm{b}_{L j}$ and right limit $\mathrm{b}_{R j}$ and conveyance parameter lies between left limit $\mathrm{e}_{L k}$ and right limit $\mathrm{e}_{R k}$.

\section{FORMULATION OF THE CRISP OBJECTIVE FUNCTION $[1,3]$}

In this section, the formulation of original interval objective function has been made as a crisp one.

Definition 3.1 $x^{0} \in S$ is an optimal solution of the problem-I iff there is no other solution $\mathrm{x} \in \mathrm{S}$ which satisfies $\mathrm{Z}(\mathrm{x})<_{L R} \mathrm{Z}\left(\mathrm{x}^{0}\right)$ or $\mathrm{Z}(\mathrm{x})<_{C W}$ $\mathrm{Z}\left(\mathrm{x}^{0}\right)$.

Theorem 3.1 It can be proved that

$$
\begin{aligned}
& \mathrm{A} \leq_{R C} \mathrm{~B} \text { iff } \mathrm{A} \leq_{L R} \mathrm{~B} \text { or } \mathrm{A} \leq_{C W} \mathrm{~B}, \mathrm{~A} \\
& <_{R C} \mathrm{~B} \text { iff } \mathrm{A}<_{L R} \mathrm{~B} \text { or } \mathrm{A}<_{C W} \mathrm{~B}
\end{aligned}
$$

where the order relation $\leq_{R C}$ is defined as A

$\leq_{R C}$ B iff $\mathrm{a}_{R} \leq \mathrm{b}_{R}$ and $\mathrm{a}_{C} \leq \mathrm{b}_{C}$,

$\mathrm{A}<{ }_{R C} \mathrm{~B}$ iff $\mathrm{A} \leq_{R C} \mathrm{~B}$ and $\mathrm{A} \neq \mathrm{B}$.

Using the theorem 3.1, Definition 3.1 is simplified as follows.

Definition $3.2 \times{ }^{0} \in S$ is an optimal solution of the Problem-I iff there is no other solution $x \in S$ which satisfies $\mathrm{Z}(\mathrm{x})<{ }_{R C} \mathrm{Z}\left(\mathrm{x}^{0}\right)$.

The right limit $\mathrm{Z}_{R}^{P}(\mathrm{x})$ of the interval objective function in problem-I is arrived as

$$
\begin{aligned}
& \mathrm{Z}_{R}^{p}(\mathrm{x}) \quad=\sum_{i=1}^{m} \sum_{j=1}^{n} \sum_{k=1}^{l} \mathrm{c}_{C i j k}^{p} \mathrm{x}_{\mathrm{ijk}}+ \\
& \sum_{i=1}^{m} \sum_{j=1}^{n} \sum_{k=1}^{l} \mathrm{c}_{W i j k}^{p}\left|x_{i j k}\right|
\end{aligned}
$$

where $c_{C i j k}^{p}$ is the centre and $c_{W i j k}^{p}$ is the half width of the coefficient of $\mathrm{x}_{\mathrm{ijk}}$ in $\mathrm{Z}^{p}$. In the case when $x_{i j k} \geq 0, i=1,2,3, \ldots, m, j=1,2,3, \ldots, n$, $\mathrm{k}=1,2,3, \ldots, 1, \quad \mathrm{Z}_{R}^{P}(\mathrm{x})$ is modified as:

$$
\begin{aligned}
& \mathrm{Z}_{R}^{p}(\mathrm{x})=\sum_{i=1}^{m} \sum_{j=1}^{n} \sum_{k=1}^{l} \mathrm{c}_{C i j k}^{p} \mathrm{x}_{\mathrm{ijk}}+ \\
& \sum_{i=1}^{m} \sum_{j=1}^{n} \sum_{k=1}^{l} \mathrm{c}_{W i j k}^{p} \mathrm{x}_{\mathrm{ijk} .}
\end{aligned}
$$

(8)

The centre of the objective function $\mathrm{Z}_{C}^{p}(\mathrm{x})$ for the Problem-I can be defined as

$$
\mathrm{Z}_{C}^{p}(\mathrm{x})=\sum_{j=1}^{n} \sum_{k=1}^{l} \mathrm{c}_{C i j k}^{p} \mathrm{x}_{\mathrm{ijk}}
$$

The solution set of the Problem-I defined by Definition 3.2 is als o obtained as the Pareto optimal solution of the two multi-objective problem as: 
Minimize $\left\{\mathrm{Z}_{R}^{p}, \quad \mathrm{Z}_{C}^{p}\right\}, \quad \mathrm{p}=1,2,3, \ldots, \mathrm{P}$, subject to the constraints (2) - (5) respectively where $\mathrm{Z}_{R}^{p}(\mathrm{x})$ and $\mathrm{Z}_{C}^{p}(\mathrm{x})$ are as stated as in equations (8) and (9).

\section{FORMULATION OF THE CRISP CONSTRAINT}

By using the theory of interval arithmetic $[3,23]$, the Problem-I is converted into its equivalent form as is as follows .

Problem -II: Minimize

$$
\mathrm{Z}^{p}=\sum_{i=1}^{m} \sum_{j=1}^{n} \sum_{k=1}^{l}\left[\mathrm{c}_{L i j k}^{p}, \mathrm{c}_{R i j k}^{p}\right] \mathrm{x}_{\mathrm{ijk}},
$$$$
\mathrm{p}=1,2,3, \ldots, \mathrm{P}
$$

subject to

$\sum_{j=1}^{n} \sum_{k=1}^{l} \mathrm{x}_{\mathrm{ijk}} \geq \mathrm{a}_{L i}, \mathrm{i}=1,2,3, \ldots, \mathrm{m}$.

$\sum_{j=1}^{n} \sum_{k=1}^{l} \mathrm{x}_{\mathrm{ijk}} \leq \mathrm{a}_{R i}, \mathrm{i}=1,2,3, \ldots, \mathrm{m}$.

$\sum_{i=1}^{m} \sum_{k=1}^{l} \mathrm{x}_{\mathrm{ijk}} \geq \mathrm{b}_{L j}, \mathrm{j}=1,2,3, \ldots, \mathrm{n}$.

$\sum_{i=1}^{m} \sum_{k=1}^{l} \mathrm{x}_{\mathrm{ijk}} \leq \mathrm{b}_{R j}, \mathrm{j}=1,2,3, \ldots, \mathrm{n}$.

$\sum_{i=1}^{m} \sum_{j=1}^{n} \mathrm{x}_{\mathrm{ijk}} \geq \mathrm{e}_{L k}, \mathrm{k}=1,2,3, \ldots, 1$.

$\sum_{i=1}^{m} \sum_{j=1}^{n} \mathrm{x}_{\mathrm{ijk}} \leq \mathrm{e}_{R k}, \mathrm{k}=1,2,3, \ldots, 1$.

$$
\mathrm{x}_{\mathrm{ijk}} \geq 0, \text { for all } \mathrm{i}, \mathrm{j}, \mathrm{k} .
$$

The problem proposed in this paper is concerned, the values of the parameters $\mathrm{c}_{C i j k}^{p}$, $\mathrm{c}_{W i j k}^{p}, \mathrm{a}_{L i}, \mathrm{a}_{R i}, \mathrm{~b}_{L j}, \mathrm{~b}_{R j}, \mathrm{e}_{L k}$ and $\mathrm{e}_{R k}$ are in the form of stochastic variables that follow certain probability distributions. Now the MOISTP in certain environment becomes a stochastic and hence the transportation model becomes a stochastic interval one. In this situation, it is difficult to handle the problem by certain known methods, and hence the probability theory has been employed to solve the problems with randomness. To satisfy the requirements of randomness, different types of stochastic programming models have been developed to suit the different purposes. Here we use the chance constrained programming developed by Charnes and Cooper [9] as a means of handling uncertainty by specifying a confidence level at which the stochastic constraints are desirable. Then Liu [22] generalized a chance constrained programming for stochastic constraints and stochastic objectives. Usually there exists multiple events in a complex stochastic decision system and the decision makers wish to maximize the chance functions.

\section{CHANCE CONSTRAINED PROGRAMMING MODEL [CCPM]}

The most popular technique is a Chance Constrained Programming (CCP) developed by Charnes and Cooper [8, 10], offers a powerful means of modeling stochastic decision systems with the assumption that the stochastic constraints holds at least ' $\alpha$ ' of time, where ' $\alpha$ ' is referred as the confidence level provided as an appropriate safety margin by the decision maker. The main idea of chance constrained programming is to optimize the critical value of the objective function under the probability constraints.

Definition 5.1 Let ' $\xi$ ' be a random variable, and $\alpha \in(0,1]$. Then

$$
\xi_{\text {inf }}(\alpha)=\inf \{\mathrm{r} \mid \operatorname{Pr}\{\xi \leq \mathrm{r}\} \geq \alpha\} \text { is }
$$

called $\alpha$-critical value of $\xi$ [22].

The CCPM for the Problem-II to seek a suitable transportation plan is as follows.

Problem -III: minimize

$\mathrm{Z}^{p}=\sum_{i=1}^{m} \sum_{j=1}^{n} \sum_{k=1}^{l}\left[\mathrm{c}_{L i j k}^{p}, \mathrm{c}_{R i j k}^{p}\right] \mathrm{x}_{\mathrm{ijk}}$,

subject to:

$$
\begin{aligned}
& \operatorname{Pr}\left\{\sum_{j=1}^{n} \sum_{k=1}^{l} \mathrm{x}_{\mathrm{ijk}} \geq \mathrm{a}_{L i}\right\} \geq \alpha_{\mathrm{Li}} \\
& \operatorname{Pr}\left\{\sum_{j=1}^{n} \sum_{k=1}^{l} \quad \mathrm{x}_{\mathrm{ijk}} \leq \mathrm{a}_{R i}\right\} \geq \alpha_{\mathrm{Ri}}
\end{aligned}
$$


$\operatorname{Pr}\left\{\sum_{i=1}^{m} \sum_{k=1}^{l} \mathrm{x}_{\mathrm{ijk}} \geq \mathrm{b}_{L j} \quad\right\} \geq \beta_{\mathrm{Lj}}$

$\operatorname{Pr}\left\{\sum_{i=1}^{m} \sum_{k=1}^{l} \mathrm{x}_{\mathrm{ijk}} \leq \mathrm{b}_{R j} \quad\right\} \geq \beta_{\mathrm{Rj}}$

$\operatorname{Pr}\left\{\sum_{i=1}^{m} \sum_{j=1}^{n} \mathrm{x}_{\mathrm{ijk}} \geq \mathrm{e}_{L k}\right\} \geq \gamma_{\mathrm{Lk}}$

$\operatorname{Pr}\left\{\sum_{i=1}^{m} \sum_{j=1}^{n} \mathrm{x}_{\mathrm{ijk}} \geq \mathrm{e}_{R k}\right\} \geq \gamma_{\mathrm{Rk}}$ (22), where $\mathrm{x}_{\mathrm{ijk}} \geq 0$, for $\mathrm{i}=1,2,3, \ldots, \mathrm{m}, \mathrm{j}=1,2,3, \ldots$, $\mathrm{n}, \mathrm{k}=1,2,3, \ldots, 1$ and $\mathrm{p}=1,2,3, \ldots, \mathrm{P}$.

The models developed in the previous sections are constructed under stochastic environment. In order to find the suitable solution for the models, critical value or credibility measure must be calculated. If the stochastic parameters are complex, the computing objective values subject to the constraints becomes a time consuming one. Due to this, it is better to convert the models into their crisp equivalents by using the appropriate probability levels defined by the decision makers

\section{CRISP EQUIVALENTS OF THE CCPM FOR MOISTP}

Theorem 6.1 Suppose that ' $\xi$ ' is a random variable with continuous probability distribution function $\phi(\mathrm{x})$, and the function

$$
\mathrm{g}(\mathrm{x}, \xi)=\mathrm{h}(\mathrm{x})-\xi \text {. }
$$

Then for any $\alpha \in(0,1]$, we have $\operatorname{Pr}\{$ $\mathrm{g}(\mathrm{x}, \xi) \leq 0\} \geq \alpha$ if and only if $\mathrm{h}(\mathrm{x}) \leq \mathrm{F}_{\alpha}$, where $\mathrm{F}_{\alpha}=\sup \left\{\mathrm{F} \mid \mathrm{F}=\phi^{-1}(1-\alpha)\right\}[1]$.

Theorem 6.2 Suppose that ' $\xi$ ' is a random variable with continuous probability distribution function $\phi(\mathrm{x})$, and the function

$$
\mathrm{g}(\mathrm{x}, \xi)=\mathrm{h}(\mathrm{x})-\xi .
$$

Then for any $\alpha \in(0,1]$, it becomes

$\operatorname{Pr}\{\mathrm{g}(\mathrm{x}, \xi) \geq 0\} \geq \alpha$ if and only if $\mathrm{h}(\mathrm{x}) \geq \mathrm{F}_{\alpha}$ , where $\mathrm{F}_{\alpha}=\inf \left\{\mathrm{F} \mid \mathrm{F}=\phi^{-1}(\alpha)\right\}$.

Theorem 6.3 Let ' $\xi$ ' be a random variable with continuous, strictly increasing probability distribution function $\phi(\mathrm{x})$. The $\alpha$ - critical value of $\xi$ is $\xi_{\text {inf }}(\alpha)=\phi^{-1}(\alpha)$.
Theorem 6.4 Let ' $\xi$ ' be a normally distributed random variable with $\xi \sim \mathrm{N}\left(\mu, \sigma^{2}\right)$. Then $\alpha$ - critical value of $\xi$ is $\xi_{\text {inf }}(\alpha)=\sigma \phi$ ${ }^{1}(\alpha)+\mu$, where $\phi(\mathrm{x})$ is the probability distribution function of standard normal distribution $\mathrm{N}(0,1)$.

By using the above theorems, the crisp equivalent of the Problem -III is obtained as follows:

Suppose that $\mathrm{c}_{C i j k}^{p}, \mathrm{c}_{W i j k}^{p}$ are independent normally distributed random variables defined $\operatorname{as~c}_{C i j k}^{p} \sim \mathrm{N}\left(\mu_{C_{C i j k}^{p}}, \sigma C_{C i j k}^{p}\right), \mathrm{c}_{W i j k}^{p} \sim \mathrm{N}$ $\left(\mu_{C_{W i j k}^{p}}, \quad \sigma_{C_{W i j k}^{p}}^{2}\right)$ and $\mathrm{a}_{L i}, \mathrm{a}_{R i}, \mathrm{~b}_{L j}, \mathrm{~b}_{R j}$, $\mathrm{e}_{L k}$ and $\mathrm{e}_{R k}$ are random variables with continuous probability distribution functions $\phi_{a_{L i}}(\mathrm{x}), \quad \phi_{a_{R i}}(\mathrm{x}), \quad \phi_{b_{L j}}(\mathrm{x}), \quad \phi_{b_{R j}}(\mathrm{x})$, $\phi_{c_{L k}}(\mathrm{x})$ and $\phi_{c_{R k}}(\mathrm{x})$, respectively, where $\mathrm{i}=$ $1,2,3, \ldots, \mathrm{m}, \mathrm{j}=1,2,3, \ldots, \mathrm{n}, \mathrm{k}=1,2,3, \ldots, 1$. Then the Problem -III is converted into its equivalent model as follows:

Problem -IV minimize

$\mathrm{Z}^{p}=\sum_{i=1}^{m} \sum_{j=1}^{n} \sum_{k=1}^{l}\left[\mathrm{c}_{L i j k}^{p}, \mathrm{c}_{R i j k}^{p}\right] \mathrm{x}_{\mathrm{ijk}}$, subject to:

$$
\begin{aligned}
& \sum_{j=1}^{n} \sum_{k=1}^{l} \mathrm{x}_{\mathrm{ijk}} \geq \mathrm{F}_{\alpha}{ }_{L i} \\
& \sum_{j=1}^{n} \sum_{k=1}^{l} \mathrm{x}_{\mathrm{ijk}} \leq \mathrm{F}_{\alpha_{R i}} \\
& \sum_{i=1}^{m} \sum_{k=1}^{l} \mathrm{x}_{\mathrm{ijk}} \geq \mathrm{F}_{\beta}{ }_{L j} \\
& \sum_{i=1}^{m} \sum_{k=1}^{l} \mathrm{x}_{\mathrm{ijk}} \leq \mathrm{F}_{\beta} R j \\
& \sum_{i=1}^{m} \sum_{j=1}^{n} \mathrm{x}_{\mathrm{ijk}} \geq \mathrm{F}_{\gamma_{L k}} \\
& \sum_{i=1}^{m} \sum_{j=1}^{n} \mathrm{x}_{\mathrm{ijk}} \leq \mathrm{F}_{\gamma_{R k}}
\end{aligned}
$$

where $x_{i j k} \geq 0$, for $i=1,2,3, \ldots, m, j=1,2,3, \ldots$, $\mathrm{n}, \mathrm{k}=1,2,3, \ldots, 1$ and $\mathrm{p}=1,2,3, \ldots, \mathrm{P}$. 


$$
\begin{gathered}
\mathrm{F}_{\alpha_{L i}}=\inf \left\{\mathrm{F} \mid \mathrm{F}=\phi_{a_{L i}}^{-1}\left(\alpha_{\mathrm{Li}}\right)\right\}, \\
\mathrm{F}_{\alpha_{R i}}=\sup \left\{\mathrm{F} \mid \mathrm{F}=\phi_{a_{R i}}^{-1}\left(1-\alpha_{\mathrm{Ri}}\right)\right\}, \\
\mathrm{F}_{\beta_{L j}}=\inf \left\{\mathrm{F} \mid \mathrm{F}=\phi_{b_{L j}}^{-1}\left(\beta_{\mathrm{Lj}}\right)\right\}, \\
\mathrm{F}_{\beta}=\sup \left\{\mathrm{F} \mid \mathrm{F}=\phi_{b_{R j}}^{-1}\left(1-\beta_{\mathrm{Rj}}\right)\right\}, \\
\mathrm{F}_{\gamma_{L k}}=\inf \left\{\mathrm{F} \mid \mathrm{F}=\phi_{e_{L k}}^{-1}\left(\gamma_{\mathrm{Lk}}\right)\right\} \text { and } \\
\mathrm{F}_{\gamma_{R k}}=\sup \left\{\mathrm{F} \mid \mathrm{F}=\phi_{e_{R k}}^{-1}\left(1-\gamma_{\mathrm{Rk}}\right)\right\} .
\end{gathered}
$$

The crisp equivalents of six probability constraints in the above model can be obtained by using the theorems defined earlier. Generally six kinds of probability constraints in ProblemIV are transformed into their crisp equivalents. But, if the probability distribution functions $\phi_{a_{L i}}(\mathrm{x}), \quad \phi_{a_{R i}}(\mathrm{x}), \quad \phi_{b_{L j}}(\mathrm{x}), \quad \phi_{b_{R j}}(\mathrm{x})$, $\phi_{c_{L k}}(\mathrm{x})$ and $\phi_{c_{R k}}(\mathrm{x})$ are complex, it is difficult to do so and hence, the following random simulation has been used to obtain the approximate values of $\mathrm{F}_{\alpha}{ }_{L i}, \mathrm{~F}_{\alpha}, \mathrm{F}_{\beta}, \mathrm{F}_{\beta}{ }_{R j}$ $\mathrm{F}_{\gamma_{L k}}$ and $\mathrm{F}_{\gamma_{R k}}$, for $\mathrm{i}=1,2,3, . ., \mathrm{m} ., \mathrm{j}=1,2,3, . ., \mathrm{n}$ and $\mathrm{k}=1,2,3, . ., 1$.

Compute $\quad \mathrm{F}_{\alpha R i}\left(\right.$ or $\mathrm{F}_{\beta_{R j}}$ or $\mathrm{F}_{\gamma_{R k}}$ ) by random simulation.

Step 1. Generate the numbers $n_{1}, n_{2}$, $\mathrm{n}_{3}, \ldots, \mathrm{n}_{N}$ according to the probability distribution function or $\phi_{a_{R i}}(\mathrm{x})$ ( or $\phi_{b_{R j}}(\mathrm{x})$ or $\left.\phi_{c_{R k}}(\mathrm{x})\right)$.

Step 2. Let $\mathrm{F}_{\alpha_{R i}}$ (or $\mathrm{F}_{\beta}$ or $\mathrm{F}_{\gamma_{R k}}$ ) be the N'th largest number in $\left\{\mathrm{n}_{1}, \mathrm{n}_{2}\right.$, $\left.\mathrm{n}_{3}, \ldots, \mathrm{n}_{N}\right\}$, where $\mathrm{N}^{\prime}=\left[\alpha_{\mathrm{i}} \mathrm{N}\right]+1\left(\right.$ or $\left[\gamma_{\mathrm{k}} \mathrm{N}\right]$ +1 or $\left[\alpha_{\mathrm{Ri}} \mathrm{N}\right]+1$ or $\left[\gamma_{\mathrm{Rk}} \mathrm{N}\right]+1$

or $\left.\left[\beta_{\mathrm{Rj}} \mathrm{N}\right]+1\right)$.

Step 3. Return $\quad \mathrm{F}_{\alpha i}$ ( or $\mathrm{F}_{\beta}$ or $\mathrm{F}_{\gamma_{R k}}$ ).

Compute $\mathrm{F}_{\alpha_{L i}}$ (or $\mathrm{F}_{\beta}$ or $\mathrm{F}_{\gamma_{L k}}$ ) by random simulation.
Step 1. Generate the numbers $\mathrm{n}_{1}, \mathrm{n}_{2}$, $\mathrm{n}_{3}, \ldots, \mathrm{n}_{N}$ according to the probability distribution function (or $\phi_{a_{R i}}$ (x) ( or $\phi_{b_{R j}}(\mathrm{x})$ or $\left.\phi_{c_{R k}}(\mathrm{x})\right)$.

Step 2. Let $\mathrm{F}_{\alpha i}\left(\right.$ or $\mathrm{F}_{\beta}{ }_{L j}$ or $\left.\mathrm{F}_{\gamma_{L k}}\right)$ be the N'th smallest number in $\left\{\mathrm{n}_{1}, \mathrm{n}_{2}, \mathrm{n}_{3}, \mathrm{n}_{N}\right\}$, where $\mathrm{N}^{\prime}=\left[\beta_{\mathrm{j}} \mathrm{N}\right]+1\left(\right.$ or $\left[\alpha_{\mathrm{Li}} \mathrm{N}\right]+1$ or $\left[\gamma_{\mathrm{Lk}} \mathrm{N}\right]$ +1 or $\left.\left[\beta_{\mathrm{Lj}} \mathrm{N}\right]+1\right)$.

Step 3. Return $\mathrm{F}_{\alpha}{ }_{L i}\left(\right.$ or $\mathrm{F}_{\beta}{ }_{L j}$ or $\left.\mathrm{F}_{\gamma_{L k}}\right)$.

After finding the crisp equivalent of the models developed earlier the following steps are used to calculate the minimum value of ' $\mathrm{P}$ ' objective functions in each of the model as follows:

\section{FUZZY PROGRAMMING APPROACH FOR THE SOLUTION OF MOISTP}

The CCPM for MOISTP can be considered as a vector minimum problem. The first step to solve the problem is to assign, for each objective, two values $\mathrm{U}^{p}$ and $\mathrm{L}^{p}$ as upper and lower bounds, respectively, for the $\mathrm{p}$-th objective, where $\mathrm{U}^{p}$ is the highest acceptable level for achievement for the p-th objective, $\mathrm{L}^{p}$ is the aspired level of achievement for the $\mathrm{p}$-th objective and $\mathrm{d}^{p}=$ $\mathrm{U}^{p}-\mathrm{L}^{p}$ is the degradation allowance for the $\mathrm{p}$ th objective. Once the aspiration levels and degradation allowance for each objective have been specified, we have formed the fuzzy model and then convert the fuzzy model into a crisp model. The steps of the fuzzy programming approach may be summarized as follows.

\section{Algorithm:}

Step 1. Solve the multi-objective interval solid transportation problem using one objective at a time (ignoring all others) subject to the given set of constraints by using any one of the suitable evolutionary technique. Let $\mathrm{X}^{1^{*}}=\left\{\mathrm{x}_{i j k}^{1}\right\}, \mathrm{X}^{2^{*}}=$ $\left\{\mathrm{x}_{i j k}^{2}\right\}, \mathrm{X}^{3^{*}}=\left\{\mathrm{x}_{i j k}^{3}\right\}, \ldots, \mathrm{X}^{P^{*}}=\left\{\mathrm{x}_{i j k}^{p}\right\}$ be the optimum solutions for $\mathrm{P}$ different single objective interval solid transportation problems.

Step 2. From the results of step1, the values of all the objective functions will be calculated at all these ' $\mathrm{P}$ ' optimal points. Then a payoff matrix is 
formed. The diagonal of the matrix constitutes individual optimum minimum values for the $\mathrm{P}$ objectives. The ' $\mathrm{X} P^{P^{*}, \text { 's }}$ are the individual optimal solutions and each of these are used to determine the values of other individual objectives, thus the payoff matrix is developed as follows:

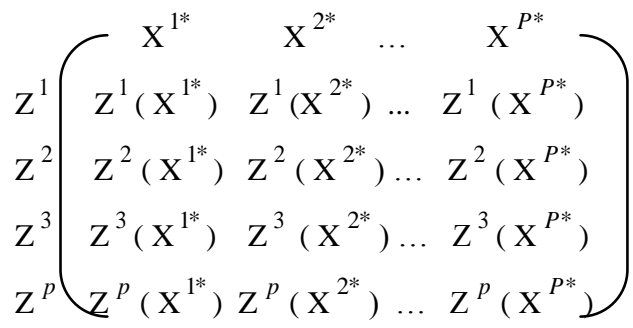

We find the upper and lower bound for each objective from the payoff matrix. Here $\mathrm{L}^{p}=$ $\mathrm{Z}^{p}\left(\mathrm{X}^{P^{*}}\right)$ and $\mathrm{U}^{p}=\max \left\{\mathrm{Z}^{p}\left(\mathrm{X}^{1^{*}}\right), \mathrm{Z}^{p}(\right.$ $\left.\left.\mathrm{X}^{2^{*}}\right), \ldots, \mathrm{Z}^{p}\left(\mathrm{X}^{P^{*}}\right)\right\}$.

Step 3. The initial fuzzy model is given by the aspiration level with each objective as follows.Find $\mathrm{x}_{\mathrm{ijk}} \mathrm{i}=1,2,3, \ldots, \mathrm{m}, \mathrm{j}=1,2,3, \ldots, \mathrm{n}$ and $\mathrm{k}=1,2,3, \ldots, 1$, so as to satisfy $\mathrm{Z}^{p} \leq \mathrm{L}^{p}$ where $\mathrm{p}=1,2,3, \ldots, \mathrm{P}$, and the given constraints and non-negativity conditions.

Step 4. For the multi-objective interval solid transportation, a membership function $\mu^{p}\left(\mathrm{Z}^{p}\right)$ corresponding to $\mathrm{p}$-th criterion is defined as

$$
\mu^{p}\left(\mathrm{Z}^{p}\right)=\left(\begin{array}{rc}
1 \quad & \text { if } \mathrm{Z}^{p} \leq \mathrm{L}^{p} \\
\left(\frac{U^{p}-Z^{p}}{U^{p}-L^{p}}\right) & \text { If } \mathrm{L}^{p}<\mathrm{Z}^{p}<\mathrm{U}^{p} \\
0 & \text { if } \mathrm{Z}^{p} \geq \mathrm{U}^{p},
\end{array}\right.
$$

Where $\mathrm{U}^{p} \neq \mathrm{L}^{p}$ forall $\mathrm{p}$. If $\mathrm{U}^{p}=\mathrm{L}^{p}$ for all $\mathrm{p}$ then $\mu^{p}\left(\mathrm{Z}^{p}\right)=1$ for all $\mathrm{p}$.

Step 5. Formulate a fuzzy linear programming problem. By using max-min operator, the equivalent fuzzy linear programming problem for the multi-objective interval solid transportation problem is formulated as follows:

For right limit of the objective function $\mathrm{Z}_{R}^{P}(\mathrm{x})$, the fuzzy linear programming problem is obtained as

$$
\begin{aligned}
& \sum_{i=1}^{m} \sum_{j=1}^{n} \sum_{k=1}^{l}\left\{\mathrm{c}_{C i j k}^{p}+\mathrm{c}_{W i j k}^{p}\right\} \mathrm{x}_{\mathrm{ijk}}+\lambda\left(\mathrm{U}^{p}-\right. \\
& \left.\mathrm{L}^{p}\right) \leq \mathrm{U}^{p}, \mathrm{p}=1,2,3, \ldots, \mathrm{P}, \text { with the given }
\end{aligned}
$$
constraints and $\lambda \geq 0$, where $\lambda=\min$ $\left\{\mu^{p}\left(\mathrm{Z}^{p}\right)\right\}$.

For the centre of the objective function $\mathrm{Z}_{C}^{p}(\mathrm{x})$, the fuzzy linear programming problem is obtained as Maximize $\lambda$ subject to $\sum_{i=1}^{m} \sum_{j=1}^{n} \sum_{k=1}^{l} \mathrm{c}_{C i j k}^{p} \mathrm{x}_{\mathrm{ijk}}+\lambda\left(\mathrm{U}^{p}-\mathrm{L}^{p}\right) \leq$ $\mathrm{U}^{p}, \mathrm{p}=1,2,3, \ldots, \mathrm{P}$, with the given constraints and $\lambda \geq 0$, where $\lambda=\min \left\{\mu^{p}\left(\mathrm{Z}^{p}\right)\right\}$.

Find out an optimal solution of the foregoing problem by using any existing method. Substituting this optimal value in each objective we get an optimal compromise interval of each objective.

\section{CASES OF CCPM FOR MOISTP}

Two different cases that may arise in CCPM for MOISTP can be described as follows.

8.1 Case-I. When the objective functions' coefficients of $\mathrm{c}_{i j k}^{p}$ are in the form of stochastic intervals, i.e., $\mathrm{c}_{i j k}^{p}=\left[\mathrm{c}_{\text {Lijk }}^{p}, \mathrm{c}_{\text {Rijk }}^{p}\right]$, and the source, destination and conveyance parameters are in the form of random variables, the multiobjective interval solid transportation problem can be represented as follows.

$$
\begin{gathered}
\mathrm{Z}^{p}=\sum_{i=1}^{m} \sum_{j=1}^{n} \sum_{k=1}^{l}\left[\mathrm{c}_{\text {Lijk }}^{p}, \mathrm{c}_{\text {Rijk }}^{p}\right] \mathrm{x}_{\mathrm{ijk}}, \\
\mathrm{p}=1,2,3, \ldots, \mathrm{P} .
\end{gathered}
$$

subject to

$$
\begin{aligned}
& \sum_{j=1}^{n} \sum_{k=1}^{l} \mathrm{x}_{\mathrm{ijk}} \leq \mathrm{a}_{\mathrm{i}} \\
& \sum_{i=1}^{m} \sum_{k=1}^{l} \mathrm{x}_{\mathrm{ijk}} \geq \mathrm{b}_{\mathrm{j}} \\
& \sum_{i=1}^{m} \sum_{j=1}^{n} \mathrm{x}_{\mathrm{ijk}} \leq \mathrm{e}_{\mathrm{k}}
\end{aligned}
$$


$\mathrm{x}_{\mathrm{ijk}} \geq 0$, for all $\mathrm{i}=1,2,3, \ldots, \mathrm{m}, \mathrm{j}=1,2,3, \ldots, \mathrm{n}$, $\mathrm{k}=1,2,3, \ldots, 1$, Using Eqs. (8) and (9) in (29) and using the chance constrained programming technique, the corresponding equivalent classical MOISTP can be expressed as

$\mathrm{Z}_{R}^{p}(\mathrm{x})=\sum_{i=1}^{m} \sum_{j=1}^{n} \sum_{k=1}^{l}\left[\mathrm{c}_{C i j k}^{p}+\mathrm{c}_{W i j k}^{p}\right] \mathrm{x}_{\mathrm{ijk}}$, $\mathrm{z}_{C}^{p}(\mathrm{x})=\sum_{i=1}^{m} \sum_{j=1}^{n} \sum_{k=1}^{l}\left[\mathrm{c}_{C i j k}^{p}\right] \mathrm{x}_{\mathrm{ijk}}$,

where $\mathrm{p}=1,2,3, \ldots, P$, subject to the constraints

$$
\begin{gathered}
\sum_{j=1}^{n} \sum_{k=1}^{l} \mathrm{x}_{\mathrm{ijk}} \leq \mathrm{F}_{\alpha_{i}} \\
\sum_{i=1}^{m} \sum_{k=1}^{l} \mathrm{x}_{\mathrm{ijk}} \geq \mathrm{F}_{\beta_{j}} \\
\sum_{i=1}^{m} \sum_{j=1}^{n} \mathrm{x}_{\mathrm{ijk}} \leq \mathrm{F}_{\gamma_{k}}
\end{gathered}
$$

where $x_{i j k} \geq 0$, for any $i=1,2,3, \ldots, m, j=1$, $2,3, \ldots, \mathrm{n}$ and $\mathrm{k}=1,2,3, \ldots, \mathrm{l}$. Now using fuzzy programming approach, as described in the earlier section, we can obtain the solution of the original problem which is presented in the following example.

Example 1. Minimize

$\mathrm{Z}^{1}=\sum_{i=1}^{3} \sum_{j=1}^{3} \sum_{k=1}^{2}\left[\mathrm{c}_{\text {Lijk }}^{1}, \quad \mathrm{c}_{R i j k}^{1}\right] \quad \mathrm{x}_{\mathrm{ijk}}$, $\mathrm{Z}^{2}=\sum_{i=1}^{3} \sum_{j=1}^{3} \sum_{k=1}^{2}\left[\mathrm{c}_{\text {Lijk }}^{2}, \quad \mathrm{c}_{R i j k}^{2}\right] \quad \mathrm{x}_{\mathrm{ijk}}$, subject to

$$
\begin{aligned}
& \sum_{j=1}^{3} \sum_{k=1}^{2} \mathrm{x}_{1 \mathrm{jk}} \leq \mathrm{N}(50,4), \\
& \sum_{j=1}^{3} \sum_{k=1}^{2} \mathrm{x}_{2 \mathrm{jk}} \leq \mathrm{N}(60,1), \\
& \sum_{j=1}^{3} \sum_{k=1}^{2} \quad \mathrm{x}_{3 \mathrm{jk}} \leq \mathrm{N}(55,4), \\
& \sum_{i=1}^{3} \sum_{k=1}^{2} \mathrm{x}_{\mathrm{i} 1 \mathrm{k}} \geq \exp (18), \\
& \sum_{i=1}^{3} \sum_{k=1}^{2} \mathrm{x}_{\mathrm{i} \mathrm{k} \mathrm{k}} \geq \exp (15),
\end{aligned}
$$

$$
\begin{aligned}
& \sum_{i=1}^{3} \sum_{k=1}^{2} \mathrm{x}_{\mathrm{i} 2 \mathrm{k}} \geq \exp (13) \text {, } \\
& \sum_{i=1}^{3} \sum_{j=1}^{3} \mathrm{x}_{\mathrm{ij} 1} \leq \mathrm{U}(60,80), \\
& \sum_{i=1}^{3} \sum_{j=1}^{3} x_{\mathrm{ij} 2} \leq \mathrm{U}(50,80),
\end{aligned}
$$

$\mathrm{x}_{\mathrm{ijk}} \geq 0$ for all $\mathrm{i}, \mathrm{j}=1,2,3$.and

$\mathrm{k}=1,2$. where $\left[\mathrm{c}_{\text {Lijk }}^{1}, \mathrm{c}_{\text {Rijk }}^{1}\right]$ and $\left[\mathrm{c}_{L i j k}^{2}, \mathrm{c}_{\text {Rijk }}^{2}\right]$ are interval cost for the criterians 1 and 2 respectively (Table-1, 2, 3 and Table-4). Using the equations (8) and (9) the equivalent deterministic MOISTP can be expressed as:

$$
\begin{aligned}
& \mathrm{Z}_{R}^{1}(\mathrm{x})=\sum_{i=1}^{3} \sum_{j=1}^{3} \sum_{k=1}^{2}\left[\mathrm{c}_{R i j k}^{1}\right] \mathrm{x}_{\mathrm{ijk}}, \\
& \mathrm{z}_{R}^{2}(\mathrm{x})=\sum_{i=1}^{3} \sum_{j=1}^{3} \sum_{k=1}^{2}\left[\mathrm{c}_{R i j k}^{2}\right] \mathrm{x}_{\mathrm{ijk}}, \\
& \mathrm{Z}_{C}^{1}(\mathrm{x})=\sum_{i=1}^{3} \sum_{j=1}^{3} \sum_{k=1}^{2}\left[\mathrm{c}_{C i j k}^{1}\right] \mathrm{x}_{\mathrm{ijk},} \\
& \mathrm{Z}_{C}^{2}(\mathrm{x})=\sum_{i=1}^{3} \sum_{j=1}^{3} \sum_{k=1}^{2}\left[\mathrm{c}_{C i j k}^{2}\right] \mathrm{x}_{\mathrm{ijk},}
\end{aligned}
$$

subject to

$$
\begin{aligned}
& \sum_{j=1}^{3} \sum_{k=1}^{2} \mathrm{x}_{1 \mathrm{jk}} \leq 47.44 \\
& \sum_{j=1}^{3} \sum_{k=1}^{2} \mathrm{x}_{2 \mathrm{j} \mathrm{k}} \leq 58.72 \\
& \sum_{j=1}^{3} \sum_{k=1}^{2} \mathrm{x}_{3 \mathrm{j} \mathrm{k}} \leq 52.44 \\
& \sum_{i=1}^{3} \sum_{k=1}^{2} \mathrm{x}_{\mathrm{ilk}} \geq 41.44 \\
& \sum_{i=1}^{3} \sum_{k=1}^{2} \mathrm{x}_{\mathrm{i} \mathrm{k}} \geq 34.53 \\
& \sum_{i=1}^{3} \sum_{k=1}^{2} \mathrm{x}_{\mathrm{i} 3 \mathrm{k}} \geq 29.9
\end{aligned}
$$




$$
\begin{aligned}
& \sum_{i=1}^{3} \sum_{j=1}^{3} \mathrm{x}_{\mathrm{ij} 1} \leq 62, \\
& \sum_{i=1}^{3} \sum_{j=1}^{3} \mathrm{x}_{\mathrm{ij} 2} \leq 53,
\end{aligned}
$$

$\mathrm{x}_{\mathrm{ijk}} \geq 0$ for all $\mathrm{i}, \mathrm{j}=1,2,3$ and $\mathrm{k}=1,2$.where $\mathrm{c}_{\text {Rijk }}^{1}$, $\mathrm{c}_{\text {Rijk }}^{2} \mathrm{c}_{\text {Cijk }}^{2}$ and $\mathrm{c}_{\text {Cijk }}^{2}$ are given in Table-7.

Solving this multi-objective classical solid transportation problem using fuzzy approach, the pareto optimal solution of the problem is obtained as follows:

$x_{111}=23.3151, x_{112}=16.1134, x_{121}=2.7465$,

$\mathrm{x}_{212}=2.0116, \mathrm{x}_{221}=26.8084, \mathrm{x}_{232}=29.9$,

$\mathrm{x}_{322}=4.9751, \lambda=0.7062$ and other $\mathrm{x}_{i j k}$ are zeros. $Z^{1}=[707.0726,1253.433]$ and

$Z^{2}=[646.6706,1233.307]$.

\subsection{Case-II}

When the objective function coefficients $\mathrm{c}_{i j k}^{p}$, source, destination and conveyance parameters $\mathrm{a}_{i}, \mathrm{~b}_{j}$ and $\mathrm{e}_{k}$ are in the form of stochastic intervals, the MOISTP can be formulated as:

Minimize

$$
\begin{aligned}
& \mathrm{Z}^{p}=\sum_{i=1}^{m} \sum_{j=1}^{n} \sum_{k=1}^{l}\left[\mathrm{c}_{L i j k}^{p}, \mathrm{c}_{R i j k}^{p}\right] \mathrm{x}_{\mathrm{ijk}}, \\
& \mathrm{p}=1,2,3, \ldots, \mathrm{P}
\end{aligned}
$$

subject to

$\sum_{j=1}^{n} \sum_{k=1}^{l} \mathrm{x}_{\mathrm{ijk}}=\left[\mathrm{a}_{L i}, \mathrm{a}_{R i}\right], \quad \sum_{i=1}^{m} \sum_{k=1}^{l} \mathrm{x}_{\mathrm{ijk}}$

$=\left[\mathrm{b}_{L j}, \mathrm{~b}_{R j}\right], \sum_{i=1}^{m} \sum_{j=1}^{n} \mathrm{x}_{\mathrm{ijk}}=\left[\mathrm{e}_{L k}, \mathrm{e}_{R k}\right]$.

where $x_{i j k} \geq 0$ for any $i=1,2,3, \ldots, m, j=1,2$, $3, \ldots, \mathrm{n}$ and $\mathrm{k}=1,2,3, \ldots, 1,\left[\mathrm{c}_{\text {Lijk }}^{1}, \mathrm{c}_{\text {Rijk }}^{1}\right]$ $\operatorname{and}\left[\mathrm{c}_{L i j k}^{2}, \mathrm{c}_{R i j k}^{2}\right]$ are interval cost for the criterians 1 and 2 respectively (Table-1, 2, 3 and Table-4).

Using equations (8) and (9), the MOISTP is equivalent to

minimize

$$
\begin{gathered}
\mathrm{Z}_{R}^{p}(\mathrm{x})=\sum_{i=1}^{m} \sum_{j=1}^{n} \sum_{k=1}^{l}\left[\mathrm{c}_{C i j k}^{p}+\mathrm{c}_{W i j k}^{p}\right] \mathrm{x}_{\mathrm{ijk}}, \\
\mathrm{Z}_{C}^{p}(\mathrm{x})=\sum_{i=1}^{m} \sum_{j=1}^{n} \sum_{k=1}^{l}\left[\mathrm{c}_{C i j k}^{p}\right] \mathrm{x}_{\mathrm{ijk},} \\
\mathrm{p}=1,2,3, \ldots, \mathrm{P},
\end{gathered}
$$

subject to

$$
\begin{aligned}
& \sum_{j=1}^{n} \sum_{k=1}^{l} \mathrm{x}_{\mathrm{ijk}} \geq \mathrm{F}_{\alpha_{L i}}, \\
& \sum_{j=1}^{n} \sum_{k=1}^{l} \mathrm{x}_{\mathrm{ijk}} \leq \mathrm{F}_{\alpha_{R i}}, \\
& \sum_{i=1}^{m} \sum_{k=1}^{l} \mathrm{x}_{\mathrm{ijk}} \geq \mathrm{F}_{\beta_{L j}}, \\
& \sum_{i=1}^{m} \sum_{k=1}^{l} \mathrm{x}_{\mathrm{ijk}} \quad \mathrm{F}_{\beta},
\end{aligned}
$$

$\sum_{i=1}^{m} \sum_{j=1}^{n} \mathrm{x}_{\mathrm{ijk}} \geq \mathrm{F}_{\gamma_{L k}}$,

$\sum_{i=1}^{m} \sum_{j=1}^{n} \mathrm{x}_{\mathrm{ijk}} \leq \mathrm{F}_{\gamma_{R k}}$,

where $\mathrm{x}_{\mathrm{ijk}} \geq 0$, for any $\mathrm{i}=1,2,3, \ldots, \mathrm{m}, \mathrm{j}=1$, $2,3, \ldots, \mathrm{n}$ and $\mathrm{k}=1,2,3, \ldots, 1$. The following numerical example illustrates the solution procedure of the foregoing problem.

\section{Example 2.}

$\operatorname{minimize} \mathrm{Z}^{1}=\sum_{i=1}^{3} \sum_{j=1}^{3} \sum_{k=1}^{2}\left[\mathrm{c}_{\text {Lijk }}^{1}, \mathrm{c}_{\text {Rijk }}^{1}\right]$ $\mathrm{x}_{\mathrm{ijk},}, \mathrm{Z}^{2}=\sum_{i=1}^{3} \sum_{j=1}^{3} \sum_{k=1}^{2}\left[\mathrm{c}_{L i j k}^{2}, \mathrm{c}_{R i j k}^{2}\right] \mathrm{x}_{\mathrm{ijk}}$,

subject to

$\sum_{j=1}^{3} \sum_{k=1}^{2} \mathrm{x}_{1 \mathrm{jk}}=[\mathrm{N}(32,5), \mathrm{N}(90,7)]$,

$\sum_{j=1}^{3} \sum_{k=1}^{2} \mathrm{x}_{2 \mathrm{jk}}=[\mathrm{N}(40,5), \mathrm{N}(95,7)]$,

$\sum_{j=1}^{3} \sum_{k=1}^{2} \mathrm{x}_{3 \mathrm{jk}}=[\mathrm{N}(36,7), \mathrm{N}(98,4)]$,

$\sum_{i=1}^{3} \sum_{k=1}^{2} x_{i 1 \mathrm{k}}=[\exp (13), \exp (35)]$, 
$\sum_{i=1}^{3} \sum_{k=1}^{2} \mathrm{x}_{\mathrm{i} 2 \mathrm{k}}=[\exp (11), \exp (43)]$,

$\sum_{i=1}^{3} \sum_{k=1}^{2} \mathrm{x}_{\mathrm{i} 3 \mathrm{k}}=[\exp (15), \exp (40)]$,

$\sum_{i=1}^{3} \sum_{j=1}^{3} x_{\mathrm{ij} 1}=[\mathrm{U}(45,65), \mathrm{U}(123,196)]$,

$\sum_{i=1}^{3} \sum_{j=1}^{3} x_{\mathrm{ij} 2}=[\mathrm{U}(46,80), \mathrm{U}(153,237)]$.

where $\mathrm{x}_{\mathrm{ijk}} \geq 0$, for $\mathrm{i}, \mathrm{j}=1,2,3, \mathrm{k}=1,2$. The equivalent deterministic MOISTP can be expressed as:

minimize

$$
\begin{aligned}
& \mathrm{Z}_{R}^{1}(\mathrm{x})=\sum_{i=1}^{3} \sum_{j=1}^{3} \sum_{k=1}^{2}\left[\mathrm{c}_{R i j k}^{1}\right] \mathrm{x}_{\mathrm{ijk}} \\
& \mathrm{Z}_{R}^{2}(\mathrm{x})=\sum_{i=1}^{3} \sum_{j=1}^{3} \sum_{k=1}^{2}\left[\mathrm{c}_{R i j k}^{2}\right] \mathrm{x}_{\mathrm{ijk}} \\
& \mathrm{Z}_{C}^{1}(\mathrm{x})=\sum_{i=1}^{3} \sum_{j=1}^{3} \sum_{k=1}^{2}\left[\mathrm{c}_{C i j k}^{1}\right] \mathrm{x}_{\mathrm{ijk}} \\
& \mathrm{Z}_{C}^{2}(\mathrm{x})=\sum_{i=1}^{3} \sum_{j=1}^{3} \sum_{k=1}^{2}\left[\mathrm{c}_{C i j k}^{2}\right] \mathrm{x}_{\mathrm{ijk},}
\end{aligned}
$$

subject to

$$
\begin{aligned}
& \sum_{j=1}^{3} \sum_{k=1}^{2} \mathrm{x}_{1 \mathrm{jk}} \geq 29.13, \sum_{j=1}^{3} \sum_{k=1}^{2} \mathrm{x}_{1 \mathrm{jk}} \leq 86.61 \\
& \sum_{j=1}^{3} \sum_{k=1}^{2} \mathrm{x}_{2 \mathrm{jk}} \geq 37.13, \sum_{j=1}^{3} \sum_{k=1}^{2} \mathrm{x}_{2 \mathrm{jk}} \leq 91.61
\end{aligned}
$$

$\sum_{j=1}^{3} \sum_{k=1}^{2} \mathrm{x}_{3 \mathrm{jk}} \geq 32.61, \sum_{j=1}^{3} \sum_{k=1}^{2} \mathrm{x}_{3 \mathrm{jk}} \leq 95.44$

$\sum_{i=1}^{3} \sum_{k=1}^{2} \mathrm{x}_{\mathrm{ilk}} \geq 29.93, \sum_{i=1}^{3} \sum_{k=1}^{2} \mathrm{x}_{\mathrm{ilk}} \leq 80.58$

$\sum_{i=1}^{3} \sum_{k=1}^{2} \mathrm{x}_{\mathrm{i} 2 \mathrm{k}} \geq 25.32, \sum_{i=1}^{3} \sum_{k=1}^{2} \mathrm{x}_{\mathrm{i} 2 \mathrm{k}} \leq 99.00$

$\sum_{i=1}^{3} \sum_{k=1}^{2} \mathrm{x}_{\mathrm{i} 3 \mathrm{k}} \geq 34.53, \sum_{i=1}^{3} \sum_{k=1}^{2} \mathrm{x}_{\mathrm{i} 3 \mathrm{k}} \leq 92.1$,

$\sum_{i=1}^{3} \sum_{j=1}^{3} x_{\mathrm{ij} 1} \geq 47, \quad \sum_{i=1}^{3} \sum_{j=1}^{3} \mathrm{x}_{\mathrm{ij} 1} \leq 130.3$,

$\sum_{i=1}^{3} \sum_{j=1}^{3} x_{\mathrm{ij} 2} \geq 49.4, \sum_{i=1}^{3} \sum_{j=1}^{3} x_{\mathrm{ij} 2} \leq 161.4$.

where $\mathrm{x}_{\mathrm{ijk}} \geq 0$, for $\mathrm{i}, \mathrm{j}=1,2,3, \mathrm{k}=1,2, \mathrm{c}_{\text {Rijk }}^{1}$, $\mathrm{c}_{\text {Rijk }}^{2} \mathrm{c}_{C i j k}^{2}$ and $\mathrm{c}_{C i j k}^{2}$ are given in Table-7.

Using fuzzy approach, the pareto optimal solution of the problem is obtained as

$\mathrm{x}_{111}=27.2273, \mathrm{x}_{131}=1.9027, \mathrm{x}_{211}=2.7027$,

$\mathrm{x}_{221}=4.9175, \mathrm{x}_{232}=29.5098, \mathrm{x}_{322}=22.3602$,

$\mathrm{x}_{331}=10.2498, \lambda=0.1131$ and other $\mathrm{x}_{i j k}$ are zeros. $Z^{1}=[608.5475,1215.7473]$ and

$Z^{2}=[580.5412,1155.5979]$.

Table-1. The unit direct interval cost for the first criterion by conveyance 1

\begin{tabular}{cccc}
\hline S/D & 1 & 2 & 3 \\
\hline 1 & {$[\mathrm{~N}(7,2), \mathrm{N}(15,1)]$} & {$[\mathrm{N}(5,1), \mathrm{N}(13,4)]$} & {$[\mathrm{N}(7,1), \mathrm{N}(12,2)]$} \\
2 & {$[\mathrm{~N}(10,2), \mathrm{N}(14,3)]$} & {$[\mathrm{N}(7,2), \mathrm{N}(12,3)]$} & {$[\mathrm{N}(7,2), \mathrm{N}(17,1)]$} \\
3 & {$[\mathrm{~N}(9,2), \mathrm{N}(24,2)]$} & {$[\mathrm{N}(6,3), \mathrm{N}(15,4)]$} & {$[\mathrm{N}(6,2), \mathrm{N}(15,3)]$}
\end{tabular}

Table-2. The unit direct interval cost for the first criterion by conveyance 2

\begin{tabular}{cccc}
\hline S/D & 1 & 2 & 3 \\
\hline 1 & {$[\mathrm{~N}(9,4), \mathrm{N}(12,1)]$} & {$[\mathrm{N}(7,2), \mathrm{N}(22,1)]$} & {$[\mathrm{N}(9,4), \mathrm{N}(14,2)]$} \\
2 & {$[\mathrm{~N}(9,3), \mathrm{N}(12,4)]$} & {$[\mathrm{N}(5,1), \mathrm{N}(25,4)]$} & {$[\mathrm{N}(5,1), \mathrm{N}(9,2)]$}
\end{tabular}


Table-3. The unit direct interval cost for the second criterion by conveyance 1

\begin{tabular}{rlll}
\hline S/D & 1 & 2 & 3 \\
\hline 1 & {$[\mathrm{~N}(6,2), \mathrm{N}(14,1)]$} & {$[\mathrm{N}(4,1), \mathrm{N}(14,4)]$} & {$[\mathrm{N}(8,1), \mathrm{N}(13,2)]$} \\
2 & {$[\mathrm{~N}(9,2), \mathrm{N}(15,4)]$} & {$[\mathrm{N}(7,3), \mathrm{N}(11,3)]$} & {$[\mathrm{N}(5,1), \mathrm{N}(16,2)]$} \\
3 & {$[\mathrm{~N}(8,1), \mathrm{N}(22,4)]$} & {$[\mathrm{N}(5,1), \mathrm{N}(14,2)]$} & {$[\mathrm{N}(6,1), \mathrm{N}(14,2)]$} \\
& & & \\
\hline
\end{tabular}

Table-4. The unit direct interval cost for the second criterion by conveyance 2

\begin{tabular}{|c|c|c|c|}
\hline S/D & 1 & 2 & 3 \\
\hline 1 & {$[\mathrm{~N}(7,2), \mathrm{N}(14,3)]$} & {$[\mathrm{N}(6,1), \mathrm{N}(20,2)]$} & {$[\mathrm{N}(9,2), \mathrm{N}(15$,} \\
\hline \multicolumn{4}{|l|}{ 3)] } \\
\hline 2 & {$[\mathrm{~N}(8,2), \mathrm{N}(12,3)]$} & {$[\mathrm{N}(6,1), \mathrm{N}(23,2)]$} & {$[\mathrm{N}(5,1), \mathrm{N}(9$,} \\
\hline \multicolumn{4}{|l|}{ 2)] } \\
\hline 3 & {$[\mathrm{~N}(5,2), \mathrm{N}(24,2)]$} & {$[\mathrm{N}(6,2), \mathrm{N}(11,3)]$} & {$[\mathrm{N}(7,1), \mathrm{N}(21$,} \\
\hline 3)] & & & \\
\hline
\end{tabular}

\section{CONCLUSION}

This paper proposes a solution procedure for solving chance constrained programming problem for multi-objective interval solid transportation problem under stochastic environment using fuzzy programming approach. All source availability, destination demand and conveyance capacities have been taken as stochastic intervals for each criterion. Chance constrained programming technique has been used to transform the problem into a classical multi-objective transportation problem. The main advantage of fuzzy programming is that, for a MOISTP with 'p' objective functions, this approach leads to $\mathrm{p}$ non-dominated solutions and one optimal compromise solution, whereas other algorithms leads to more than $\mathrm{p}$ non-dominated and dominated solutions from which the decision maker can choose a compromise solution.

\section{REFERENCES:}

[1] Alefeld, G. and Herzberger, 1983 J. Introduction to Interval computations, Academic Press, New York.

[2] Liu, B. 2002 Theory and Practice of Uncertain Programming, Physica-Verlag, New York.
[3] R.E.Moore, M.E. 1979 Method and Applications of Interval Analysis, SLAM, Philadephia, PA.

[4] Shell, E. 1955 Distribution of a product by several properties, Directorate of Management Analysis, Proc. $2^{\text {nd }}$ Symp. on Linear programming, Vol. 2, pp. 615-642, DCS/Comptroller H.Q. U.S.A.F., Washington, DC.

[5] Basu, M., Pal, B.B., and Kundu, A., 1994 An algorithm for optimum solution of solid fixed charge transportation problem, Optimization 31, 283-291.

[6] Bit, A.K, Biswal, M.P. and Alam, S.S. 1993 Fuzzy programming approach to multi-objective solid transportation problem, Fuzzy Sets Systems. 57, 183-194.

[7] Baoding Liu and Yian-Kui Liu, AUG 2002 Expected value of fuzzy variable and fuzzy expected value models, IEEE Transactions on Fuzzy Systems, 10(4) 445-450.

[8] Charnes, A. and Cooper, W.W. 1952 Chance-constrained and normal deviates. Journal of American Statistics Association 57, 134-118.

[9] Charnes, A. and Cooper, W.W. 1959 Chance-constrained programming. Management Science 6 (1), 73-80. 
[10] Charnes, A. and Cooper, W.W., 1963 Deterministic equivalents for optimizing and satisfying under chance constraints, Operations Research 11, 18-39.

[11] Das,S.K., Goswami, A. and .Alam, S.S. 1999 Multiobjective transportation problem with intervsl cost, source and destination parameters, European Journal of Operations Research 117, 100-112.

[12] Gen, M. Ida, K., Y.Li,Y. and Kubota, E. 1995 Solving bicriteria solid transportation problem with fuzzy numbers by a genetic algorithm, Comput. Ind. Eng. 29, 537-541.

[13] Ishibuchi, H. and Tanaka, H. 1990 multiobjective programming in optimization of the interval objective function, European Journal of Operations Research 48, 219-225.

[14] Inguichi, M. and Kume, Y. 1991 Goal programming problem with interval coefficient and target intervals, European Journal of Operations Research 52 , 345-360.

[15] Jimenez, F and Verdegay, J.L. 1998 Uncertain solid transportation problems, Fuzzy sets systems. 100, 45-57.

[16] Jimenez, F. and Verdegay, J.L. 1999 Solving fuzzy solid transportation problems by an evolutionary algorithm based parametric approach, European Journal of Operations Research, 117, 485-510.

[17] Li, Y., .Ida, K., Gen, M. and R.Kobuchi, R. 1997 Neural network approach for multi-criteria solid transportation problem, Comput. Ind. Eng. 33, 465-468.

[18] Li, Y., Ida, K. and M.Gen, M. 1997 Improved genetic algorithm for solving multi-objective solid transportation problem with fuzzy numbers, Comput. Ind. Eng. 33, 589-592.

[19] Lixing Yang and Linzhong Liu, 2007 Fuzzy fixed charge solid transportation problem and algorithm, Applied soft computing , 7, 879-889.

[20] Lixing Yang, Yuan Feng, 2007 A bi-criteria solid transportation problem with fixed charge under stochastic environment, Applied Mathematical Modeling 31, 26682683.

[21] Liberling, H. 1981 On finding compromise solutions for multicriteria problems using the fuzzy min-operator, Fuzzy Sets and Systems 6, 105-118.

[22] Liu, B. and Iwamura, K. 1998 Chance constrained programming with fuzzy parameters. Fuzzy Sets Systems. 94 (2), 227-237.

[23] Nagarajan, A. and Jeyaraman, K. March 2009-May 2009 Mathematical modeling of solid fixed cost bi-criterion indefinite quadratic transportation problem under stochastic environment, Emerging journal of engineering science and technology, Volume-02, N-03, pp.106-127.

[24] Nagarajan, A. and Jeyaraman, K, Solution of expected value model for multi-objective interval solid transportation problem under stochastic environment using fuzzy programming approach, Emerging journal of engineering science and technology. Article in press.

[25] Nagarajan, A.and Jeyaraman, K. Chance constrained goal programming models for multi-objective interval solid transportation problem under stochastic environment, International journal of applied mathematics analysis and applications. Article in press.

[26] Stuer, R.E. 1981 Algorithm for linear programming problems with interval objective function coefficient, Mathematics of Operations Research 6, 333-348.

[27] Tong, S. 1994 Interval number and fuzzy number linear programming, Fuzzy Sets and Systems 66, 301-306.

[28] Zadeh, L.A. 1965 Fuzzy sets, Information and control 8 , 338-353.

[29] Zimmerman, J. 1978 Fuzzy programming and Linear programming with several objective functions, Fuzzy Sets and Systems 1, 45-55. 